\title{
Evidence of expanding geographic distribution of melioidosis in Bangladesh: reports of three cases
}

\author{
Saha SKa ${ }^{a}$ Samad T ${ }^{b}$, Haque WMMc
}

\begin{abstract}
Melioidosis is an emerging infectious disease in Bangladesh. Reported cases are mostly diagnosed among inhabitants of central and north-east zone of the country. We report three cases of melioidosis occurring among patients with diabetes mellitus and chronic kidney disease from not well-known endemic areas within the country. Patients presented with fever, anorexia and weight loss. Laboratory reports confirmed growth of Burkholderia pseudomallei from blood and urine. These cases are reported to increase awareness among physicians regarding melioidosis occurring beyond the so-called hot spots in Bangladesh.
\end{abstract}

Key wards: Burkholderia pseudomallei, chonic kidney disease, diabetes mellitus, endemicity, melioidosis.

(BIRDEM Med J 2021; 11(3): 239-242)

\section{INTRODUCTION}

Melioidosis is caused by Burkholderia pseudomallei, a Gram-negative, environmental saprophytic bacterium found in wet soil, mud and pooled surface water in the tropics and subtropics. ${ }^{1}$ Patients with diabetes mellitus (DM) and chronic kidney disease (CKD) are at increased risk for melioidosis. ${ }^{1,2}$ Patients may present with fever, pneumonia, septicemia and visceral abscess and there is high mortality. In spite of being an endemic disease, melioidosis has not been reported frequently in Bangladesh, may be due to lack of awareness among physicians and microbiologists and inadequate diagnostic facilities. ${ }^{3}$ Reported autochthonous cases

\section{Author information}

a. Shudhanshu Kumar Saha, Registrar, Department of Nephrology, BIRDEM General Hospital, Dhaka, Bangladesh.

b. Tabassum Samad, Consultant, Department of Nephrology, BIRDEM General Hospital, Dhaka, Bangladesh.

c. Wasim Md. Mohosin Ul Haque, Associate Professor, Department of Nephrology, BIRDEM General Hospital, Dhaka, Bangladesh.

Address of correspondence: Shudhanshu Kumar Saha, Registrar, Department of Nephrology, BIRDEM General Hospital, Dhaka, Bangladesh. Email: shudhanshukumarsaha (a)gmail.com

Received: April 20, 2021

Revision received: July 13, 2021

Accepted: July 31, 2021 are mostly diagnosed among inhabitants of central and north-east zone of Bangladesh. ${ }^{4-6}$ We report three cases of melioidosis having DM and CKD hailing from not well-known endemic areas within the country.

\section{METHODS}

Patients' clinical and laboratory data were recorded in case record forms after obtaining informed written consent from patients or attendants. In-hospital treatment and outcomes were also recorded.

\section{CASE REPORTS}

Three male patients, aged between 50 and 75 years from Rajshahi (patient 1), Chattogram (patient 2) and Munshigonj (patient 3) districts, presented with fever, anorexia and weight loss (Table I, Figure 1) for variable duration. They were initially evaluated locally and received treatment including antibiotics (ciprofloxacin and ceftriaxone) without any benefit. One of them had abdominal pain. They were known to be suffering from $\mathrm{DM}$ and CKD. One of them was on prednisolone (60 $\mathrm{mg}$ /day) for glomerulonephritis (patient 2). Clinically they were febrile, anaemic and dehydrated. On abdominal examination, patient 1 had suprapubic tenderness and patient 3 had 4-cm splenomegaly.

They had neutrophilic leukocytosis, high erythrocyte sedimentation rate (ESR), C-reactive protein (CRP) and 
raised serum creatinine (Table I). All had uncontrolled diabetes (HbA1c 8-9\%) (Table I). Ultrasonography showed splenomegaly in one case (patient 3 ), prostatic abscess in another and all had contracted echogenic kidneys. Chest X-ray appeared normal in all three cases. Blood culture grew B. pseudomallei in all cases and urine culture confirmed B. pseudomallei in one of them.

Unfortunately, the patient (patient 2) with prostatic abscess died before receiving blood culture report.
Patients were treated initially with ceftazidime and meropenem (dose adjusted for kidney function) for 4 weeks and in eradication phase co-amoxiclav or co-trimoxazole and doxycycline combination. One patient required 4 sessions of hemodialysis and intensive care unit support initially. Other medications included paracetamol and blood transfusion. Patients were discharged with stable renal function.

Table I Base-line parameter, clinical and investigations profile of patients with melioidosis

\begin{tabular}{|c|c|c|c|}
\hline Parameters & Patient 1 & Patient 2 & Patient 3 \\
\hline \multicolumn{4}{|l|}{ Demographic } \\
\hline Age (years) & 50 & 57 & 75 \\
\hline Sex & male & male & male \\
\hline Address & Chottogram (urban) & Rajshahi (rural) & Munshiganj (urban) \\
\hline Occupation & businessman & farmer & businessman \\
\hline \multicolumn{4}{|l|}{ Clinical presentation } \\
\hline & fever (2 weeks) & fever (3 weeks) & fever (6 weeks) \\
\hline & vomiting altered & anorexia dysuria & weight loss \\
\hline & conscious level & dehydration suprapubic & abdominal pain \\
\hline & dehydration & tenderness & dehydration \\
\hline \multicolumn{4}{|l|}{ Biochemical } \\
\hline $\begin{array}{l}\text { Random blood glucose } \\
(\mathrm{mmol} / \mathrm{L})\end{array}$ & 10 & 12 & 8 \\
\hline HbAlc $(\%)$ & 9 & 9 & 8 \\
\hline $\mathrm{Hb}(\mathrm{gm} / \mathrm{dl})$ & 10.3 & 9.0 & 7.0 \\
\hline Total WBC & $37.370 \times 10^{9} / \mathrm{L}$ & $16350 \times 10^{9} / \mathrm{L}$ & $15.8303 \times 10^{9} / \mathrm{L}$ \\
\hline Platelet count & $364 \times 10^{9} / \mathrm{L}$ & $160 \times 10^{9} / \mathrm{L}$ & $138 \times 10^{9} / \mathrm{L}$ \\
\hline ESR & & $70 \mathrm{~mm} /$ hour & $70 \mathrm{~mm} /$ hour $90 \mathrm{~mm} /$ hour \\
\hline CRP & $207 \mathrm{mg} / \mathrm{L}$ & $207 \mathrm{mg} / \mathrm{L}$ & $125 \mathrm{mg} / \mathrm{L}$ \\
\hline Serum creatinine & $8.1 \mathrm{mg} / \mathrm{dl}$ & $7.7 \mathrm{mg} / \mathrm{dl}$ & $4.5 \mathrm{mg} / \mathrm{dl}$ \\
\hline \multicolumn{4}{|l|}{ Microbiological } \\
\hline \multirow[t]{2}{*}{ Blood culture } & Growth of $B$. & Growth of $B$. & Growth of $B$. \\
\hline & pseudomallei & pseudomallei & pseudomallei \\
\hline Urine culture & - & $\begin{array}{l}\text { Growth of } B . \\
\text { pseudomallei }\end{array}$ & - \\
\hline \multicolumn{4}{|l|}{ Radiological } \\
\hline Abdominal sonography & $\begin{array}{l}\text { bilateral echogenic } \\
\text { kidney }\end{array}$ & $\begin{array}{l}\text { prostatitis with abscess } \\
\text { formation }\end{array}$ & splenic abscess \\
\hline
\end{tabular}




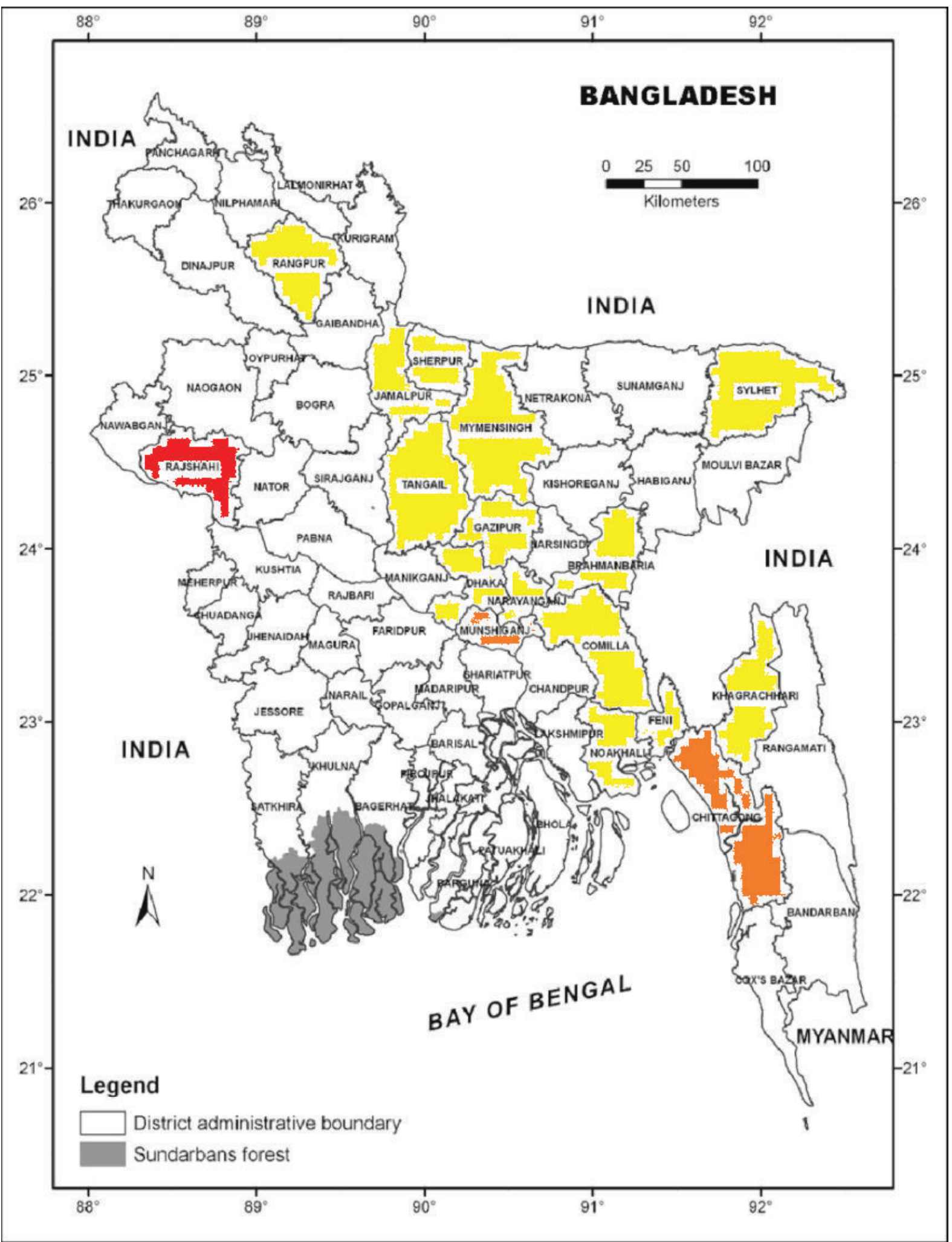

Figure 1 Districts of Bangladesh reported to have melioidosis cases (new cases - red, new and previously reported cases - orange and previously reported cases - yellow) 


\section{DISCUSSION}

Melioidosis is now recognized as a major cause of fatal septicaemia in endemic tropical regions. Patients with DM, CKD, chronic lung disease and excess alcohol intake were associated with increased risk for melioidosis. ${ }^{1,7}$

Patients with $B$. pseudomallei infection may present with fever, pneumonia, cutaneous and visceral abscess. ${ }^{3}$ CKD itself is a risk factor for melioidosis by impairing host immune response due to impaired chemotaxis of neutrophils, reduced phagocytic ability, decreased generation of reactive oxygen intermediates during oxidative burst and significant elevation of resting levels of cytosolic calcium and reduction in adenosine triphosphate of the phagocytic cells. ${ }^{8,9}$ In an Australian prospective study, $39 \%$ of patients with melioidosis had DM and $12 \%$ had CKD and in $20 \%$ cases there was no identifiable risk factor. ${ }^{7}$

In Bangladesh, there is paucity of incidence data of melioidosis cases among risk group population; sporadic cases with DM, CKD and steroid intake were reported. ${ }^{2-5,10,11}$ In Bangladesh, most endemic melioidosis cases were reported from Tangail, Mymensingh, Gazipur, Jamalpur and Sylhet districts (Figure 1) along with imported cases. ${ }^{4,5,12}$ Cases beyond this geographic distribution have rarely been reported; our reported cases draw attention that melioidosis can occur beyond the so-called hot spots of the country and physicians should have a high index of clinical suspicion in appropriate clinical settings.

Further attention is sought to the fact that, most melioidosis cases in Bangladesh were identified in microbiology laboratory of Bangladesh Institute of Research and Rehabilitation in Diabetes, Endocrine and Metabolic Disorders (BIRDEM) General Hospital in Dhaka, Bangladesh, one of the tertiary care center in Bangladesh. It is understandable that, it was possible for only those patients who could manage to come and get admitted in BIRDEM General Hospital or tested from there. It is likely that most patients remain beyond these facilities and so inappropriately evaluated. Capacity building efforts especially for microbiology facility is emphasized.

Authors' contribution: SKS, TS, WMMH managed cases. SKS drafted the manuscript. All authors read and reviewed the final manuscript before submission.

Conflicts of interest: Nothing to declare.

\section{REFERENCES}

1. Limmathurotsakul D, Golding N, Dance DA, Messina JP, Pigott DM, Moyes CL, et al. Predicted global distribution of Burkholderia pseudomallei and burden of melioidosis. Nat Microbiol 2016;1:15008.

2. Rahim MA, Khan MAY, Chowdhury TA, Ananna MA. Septicemic melioidosis complicating undiagnosed chronic kidney disease and beta-thalassemia minor in a Bangladeshi farmer. Saudi J Kidney Dis Transpl 2020;31:1411-4.

3. Rahim MA, Afroze SR, Barai L, Uddin KN. Melioidosis: Truly Uncommon or Uncommonly Diagnosed in Bangladesh? A Case Report. Birdem Med J 2015; 5 (Supplement 1): 49-51.

4. Barai L, Jilani MS, Haq JA. Melioidosis: case reports and review of cases recorded among Bangladeshi population from 1988-2014. Ibrahim Med Coll J 2015; 8(1): 25-31.

5. Afroze SR, Haque HF, Afroz F, Barai L, Rahim MA, Haque MT, et al. Sociodemographic, clinical and laboratory characteristics of melioidosis: four-year experience of managing consecutive 11 cases in a tertiary care hospital of Bangladesh. BIRDEM Med J 2017;7:28-37.

6. Chowdhury FR, Jilani MSA, Barai L, Rahman T, Saha MR, Amin MR, et al. Melioidosis in Bangladesh: A Clinical and Epidemiological Analysis of Culture-Confirmed Cases. Trop Med Infect Dis 2018; 3(2): 40.

7. Currie BJ, Ward L, Cheng AC. The epidemiology and clinical spectrum of melioidosis: 540 cases from the 20 year Darwin prospective study. PLoSNegl Trop Dis 2010; 4 (11): e900

8. Heinzelmann M, Mercer-Jones MA, Passmore JC. Neutrophils and renal failure. Am J Kidney Dis 1999; 34: 384-99.

9. Iida TK, Umezawa K, Tanaka Y, Nakazawa KH, Satoh T. Polymorphonuclear cells in chronic hemodialysis patients have intact phagocytotic and impaired bactericidal activities. Nephron 1997; 75: 41-7.

10. Rahim MA, Samad T, Ananna MA, Haque WMM. Genitourinary melioidosis in a Bangladeshi farmer with IgA nephropathy complicated by steroid-induced diabetes mellitus. Saudi J Kidney Dis Transpl 2018;29(3):709-13.

11. Majumder MI, Haque MM, Ahmed MW, Alam MN, Rahman MW, Akter F, et al. Melioidosis in an adult male. Mymensingh Med J 2013; 22: 413-6.

12. Rahim MA, Afroze SR, Afroz F, Haque HF, Barai L, Ahmed JU, et al. Melioidosis among returning workers in Bangladesh: imported or endemic? Sri Lankan J Infect Dis 2017; 7 (S27): 34-5. 